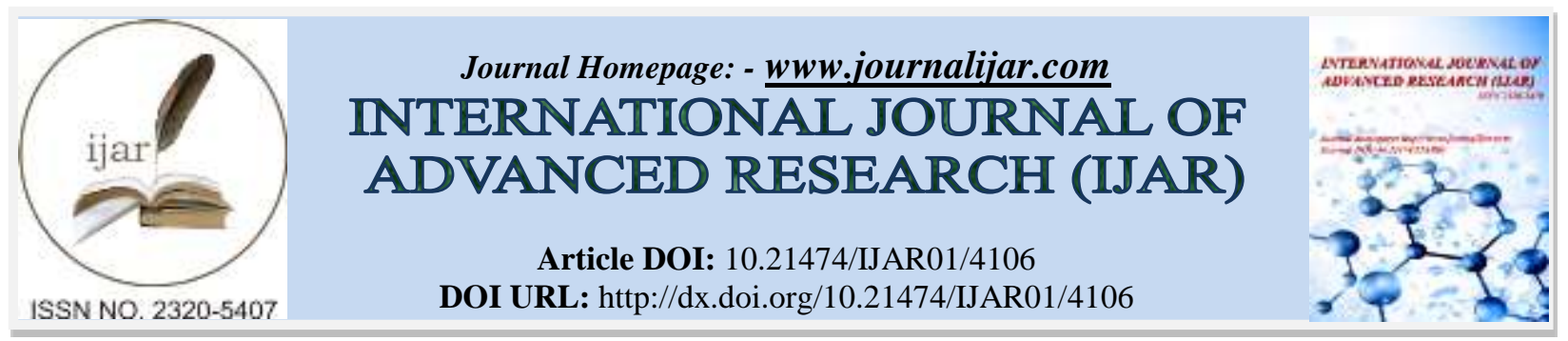

RESEARCH ARTICLE

\title{
EXPLORING SAUDI FACULTY PERCEPTIONS OF THE CHARACTERISTICS OF A GOOD FACULTY: A DELPHI STUDY.
}

\author{
Abdualrahman S. Alshehry and Homood A. Alharbi \\ PhD. MSN. RN. CCRN. Assistant Professor, College of Nursing, King Saud University, Riyadh, Saudi Arabia.
}

\section{Manuscript Info}

Manuscript History

Received: 05 March 2017

Final Accepted: 14 April 2017

Published: May 2017

\section{Key words:}

Delphi, Nursing Education,

characteristics of good faculty, Saudi

Arabia

\section{Abstract}

Background: There are many studies that explored the characteristics of a good faculty. However, none of these studies were conducted in Saudi Arabia, therefore, due to the cultural differences and the different education policy, results of these studies may not be applicable to these populations. The present study aimed to examine the characteristics of a good faculty in a nursing program in Saudi Arabia.

Methods: Twelve faculty members (male 5, female 7) from the nursing college were participated. A three round questionnaire based survey was conducted using the Delphi technique. Participants were requested to respond to an open ended question. In addition, they were requested to rate a list of 30,37 , and 42 characteristics of a good faculty in round one, two, and three survey, respectively.

Results: The top five characteristics of a good faculty in the present study were fair to all students, good academic knowledge, uses variety of teaching methods, encourage self-learning, and effective communication skills. Experts believed that both being empathetic and sympathetic are not among the characteristics of a good faculty.

Conclusion: In the present study, teaching and learning strategies, subject knowledge, and the personality attributes all were characteristics of a good faculty in the nursing college. However, academic knowledge, teaching methods, and communication skills were the top qualities of a good faculty.

Copy Right, IJAR, 2016,. All rights reserved.

\section{Introduction:-}

As cited by Bunting (2006), philosopher Aristotle defined a good teacher as one who applies talents and insights in individualized ways. Shulman (2004) said that good teachers can only be identified according to what they impart. Those who aspire to becoming good teachers begin by watching, listening to those they consider good teachers and try to apply their teaching styles (Bunting, 2006). Schools can help teachers improve by providing them time to relate with other teachers, develop themselves on their own and be accountable for what they become (Bunting, 2006). 
There is no single definition of who is a good teacher. However, many researchers define a good teacher as "...who day after day connects students to the rigors and rewards of learning" (Bunting, 2006). In another definition, Dewey (1938) defines "good teachers as artists whose practice defy notions of right and wrong, or good and bad." Another author defined great teachers as individual responders who utilize their knowledge in exceedingly individualized ways (Carr 1999). Glanz (1993), in a book review defined "good teachers, to some, are sensitive to differences among students while at the same time treating all equally and fairly."

Since, there is no consensus in the literature about the definition of a good teacher. Many scholars outlined the characteristics of a good faculty (Jenkins, 2016; Bakx et al., 2015; Gandara and Santibanez, 2016; Benekos, 2016; Taylor, 1962; Miller, 2012; Sutkin et al., 2008; Arnon and Reichel, 2007; Miron and Segal, 1978). Good teachers are energetic, knowledgeable, creative, flexible, independent, honest, and innovative (Glanz 1993). Orlando (2013) has presented nine characteristics of good teachers, including "respect for student", "enthusiasm and caring", "high expectations for students", "love of learning", and "professionalism". Manchanda (2010) has presented four characteristics of good teachers, including knowledge, interest, communication skills, and respect for students. Leblanc (1998) has presented 10 qualities of good teachers, including passionate, effectiveness in listening, questioning, and responding, flexibility and gracefulness in adapting the various circumstances, friendly, humor, and caring. Hammer and Colleagues (2010) indicated that the good teachers should have effective communication skills, give prompt feedback to students, and maintain high expectations for student achievement. Miller (2012) has discussed ten qualities of good teachers into four domains, including affective characteristics, skills, classroom management techniques, and academic knowledge. The ten characteristics of good teachers include, enthusiasm, creative, humor, challenging, encouraging, patient, interest, respect for the student, effectiveness in responding, and knowledgeable (Miller 2012).

Although, there are many studies that studied the characteristics of a good faculty. None of these studies were conducted in Saudi Arabia due to the cultural differences (Alamri, 2011) and the different education policy (Hamdan, 2014). Therefore, the present study aimed to examine the characteristics of a good faculty in a nursing program in Saudi Arabia. The final outcome of the study would provide a list of items that identify the qualities of a good faculty that would be culturally relevant to nursing in Saudi Arabia.

\section{Methods:-}

\section{Research Questions:-}

The present study address the following research question:

- What are the characteristics of a good faculty to work in the nursing college in Saudi Arabia?

\section{Setting:-}

The required data in the present study was collected from the Nursing College, King Saud University, Riyadh, Saudi Arabia. For the Delphi technique, a total of 12 faculties were requested to serve as expert panelists and to give their perceptions of the characteristics of a good faculty. The experts was represented the four departments in the nursing college (Medical Surgical, Maternity, Psychiatric, Management and Leadership). Both genders were participated.

\section{Ethical Consideration:-}

Approval of the study was obtained from the King Saud University Institutional Review Board. In addition, an explanation of the study and informed consent was provided to participants before starting the study (Friedman, Furberg, \& DeMets, 1998).

\section{Procedures for Data Collection and Analysis:-}

After official approval by the Institutional Review Boards (IRB) of King Saud University, an invitation email was sent by the researcher to the selected experts to invite them to participate in this study as expert panelists. The invitation email included the survey questionnaire and directions for completion of the survey. Expert panelists were requested to return the survey questionnaire in two weeks. Communication between the researchers and the panelists was via email only, so that no expert could exert an undue influence over the opinions of others (Nieswiadomy, 2008). Participants were known to the researcher, but were known to the other participants to keep anonymity among the participants (Dalkey, 1963; Hasson, Keeney, \& McKenna, 2000).

The survey of the first round had two sections. In the first section, expert panelists were requested to respond to an open-ended question. The question was as follow: what are the top five good characteristics of a good faculty? In 
the second section of the questionnaire, the participants were asked to rate a list of 30 characteristics of a good faculty. The lists of these characteristics were identified from a systematic review of the literature. Faculty members were requested to give their perceptions about the importance of the characteristics of a good faculty through responding to a questionnaire that was designed as a Likert-scale with a five-point response choice, on which $1=$ strongly unimportant, $2=$ unimportant, $3=$ neutral, $4=$ important, and $5=$ strongly important.

Subsequently, responses to each round was analyzed, summarized, and returned to the experts with a new questionnaire (Polit \& Beck, 2004). Feedback from each round was prepared in statistical form that included the group mean rating of each item, the minimum and maximum ratings, the standard deviation, and the frequencies of the item for the panel. Individual was reminded about his/her rating the item in the former round (Hasson et al., 2000). For each item, panelists were given these statistical measures to help them retain or revise their previous ratings. These statistics would enable the experts to see where their response located in relation to that of the group (Schmidt, 1997). A large standard deviation would indicate the large variations in panelists' rating of that item; in contrast, a small standard deviation which would reflect a small variation in panelists' rating of that item, which indicated a consensus among the panelists (Watson et al., 2008).

As in the first round, the survey in the second round would comprise two sections. In the first section, participants were requested to rate the list of factors that used in the first round, plus the factors that has been added by the expert panelists. In the second section, participants were requested to add characteristics they believed to be important to a good faculty. Subsequently, data from the second round was analyzed following the same procedure as in the first round. Responses to this round was analyzed, summarized, and returned to the experts with a new questionnaire to be used in the third round.

In analyzing the third round, any item/characteristic with an agreement level of more than $68 \%$ in this round indicated that consensus had been achieved for that factor. Hence, at least eight out of the twelve panelists was required to rate a factor with either 3 (important) or 4 (very important) for consensus to be achieved.

\section{Demographic questionnaire:-}

Prior to starting the Delphi study, panelists were requested to complete a demographic questionnaire indicating their nationality, age, gender, educational background, and years of educational experience.

\section{The Delphi Technique:-}

The Delphi technique was developed by workers at the RAND Corporation during the beginning of the Cold War to forecast the impact of technology on warfare (Dalkey \& Helmer, 1963). The Delphi technique is a data collection procedure that recruits a panel of experts to complete a series of questionnaires focusing on the experts' opinions, predictions, or judgment about a particular topic (McKenna, 1994; Nieswiadomy, 2008). The Delphi method differs from other surveys in many aspects. First, researchers using the Delphi method are not looking for experts' opinions only, but aiming to gain a consensus of these opinions (ALHussain, Murphree Jr, \& Bixler, 2012; Polit \& Beck, 2004). In addition, a Delphi technique involves multiple iterations/rounds to reach consensus without the need for face-to-face interviews. Responses to each round of questionnaires are analyzed, summarized, and returned to the experts with a new questionnaire (McKenna, 1994). The panels are then required to reformulate their opinions in light of the previous round's results (McKenna, 1994). The process of response-analysis-feedback-response is carried out for three rounds until a general consensus is achieved (Polit \& Beck, 2004).

McKenna (1994) discussed some key characteristics of the Delphi method which include: (1) the use of a panel of experts for obtaining data; (2) participants do not meet in face-to-face discussions; (3) the use of sequential questionnaires and/or interviews; (4) the systematic emergence of a concurrence of judgment/opinions; (5) the guarantee of anonymity for subjects' responses; (6) the use of frequency distributions to identify patterns of agreement; and (7) the use of two or more rounds between which, a summary of the results of the previous round is communicated to and evaluated by panel members.

There is no universal agreement about what constitutes consensus. However, Loughlin and Moore (1979) suggested that consensus should consist of an agreement by $51 \%$ or more of the panelists; Sumsion (1998) recommends $70 \%$; others have suggested 75\% (Keeney, Hasson, \& McKenna, 2006; McKenna \& Hasson, 2002); while Green, Jones, Hughes, and Williams (1999) suggest $80 \%$ agreement among participants. Even though setting a percentage level to determine what constitutes a consensus is the standard in Delphi studies (Williams \& Webb, 1994), other 
researchers rely on the spread of scores or standard deviation for each question from the mean average score (Jones \& Hunter, 1995; Passannante, Restifo \& Reichman, 1993). A wide spread of scores from the mean indicates a weak consensus among panelists, while a narrow spread of scores indicates a strong consensus (Jones \& Hunter, 1995; Passannante et al., 1993). Nevertheless, it is worth mentioning that consensus does not mean the correct answer has been found; it simply means that consensus has been achieved among a panel of participants (Watson, McKenna, Cowman, \& Keady, 2008).

\section{Sampling in the Delphi Method:-}

The Delphi technique does not use a random sample to represent the target population, but rather recruits "experts" as panel members (Watson et al., 2008). Experts are "informed individuals" specialized in the field or who have knowledge about the subject (Watson et al., 2008).

There is no universal agreement on the proper size of the panel (Watson et al., 2008). Panels have ranged in size from four to more than 3000 participants (Cantrill, Sibbald, \&Buetow, 1996); Hogarth (1978) and Mitchell (1991), however, have suggested six to 10 experts. Nevertheless, Clayton (1997) indicated that by rule of thumb, five to 10 is appropriate for heterogeneous groups and 15 to 30 for homogeneous ones. However, researchers need to consider the purpose of the investigation (Cantril et al., 1996) and the time constraints when deciding the panel size (Watson et al., 2008). The larger the panel, the more time is needed to follow up the experts' responses (Watson et al., 2008). In addition, the larger the sample size, the poorer the response rate tends to be (Watson et al., 2008).

\section{Results:- \\ Description of faculty experts:-}

Most of the expert panelists were non-Saudi females. Only two panel members were Saudi and five were males (see Table 1). The post-secondary system is heavily dependent on non-Saudi teachers because of the limited number of Saudi faculty members (Alamri, 2011; Onsman, 2011). Half of the participating faculty members in this study were from Arab countries, such as Egypt and Jordan, constituting around 50\% of the sample. Participants' ages ranged from 30 to 66 years $(M=49.5)$. Most of the faculty were assistant professors $(n=7)$, where three participants were associate professors and only two faculty were professors. Nearly $75 \%$ of the participating faculty members had more than 15 years of teaching experience and more than $66 \%$ served for more than five years teaching in Saudi Arabia. Hence, the faculty on the panel had sufficient knowledge and expertise to express an opinion about the factors promoting student retention and success.

Table 1:- Demographics Characteristics of Expert Panelists

\begin{tabular}{|c|c|c|c|}
\hline Characteristics & Frequency & Percent & Cumulative Percent \\
\hline \multicolumn{4}{|l|}{ National } \\
\hline Saudi & 2 & 16.7 & 16.7 \\
\hline Egyptian & 4 & 33.3 & 50.0 \\
\hline Jordanian & 2 & 16.7 & 66.7 \\
\hline Filipino & 3 & 25.0 & 91.7 \\
\hline Indian & 1 & 8.3 & 100.0 \\
\hline \multicolumn{4}{|l|}{ Gender } \\
\hline Male & 5 & 41.7 & 41.7 \\
\hline Female & 7 & 66.7 & 100 \\
\hline \multicolumn{4}{|c|}{ Years of Teaching Experience } \\
\hline $1-5$ & 1 & 8.3 & 8.3 \\
\hline $6-10$ & 1 & 8.3 & 16.7 \\
\hline $11-15$ & 1 & 8.3 & 25.0 \\
\hline$>15$ & 9 & 75.0 & 100 \\
\hline \multicolumn{4}{|c|}{ Years of Teaching Experience in Saudi Arabia } \\
\hline $1-5$ & 4 & 33.3 & 33.3 \\
\hline $6-10$ & 3 & 25.0 & 58.3 \\
\hline
\end{tabular}




$\begin{array}{llll}11-15 & 4 & 33.3 & 91.7 \\ >15 & 1 & 8.3 & 100\end{array}$

\section{Round One:-}

Round one of the Delphi survey consisted of three sections. The first section contained demographic survey items. In the second section, expert panelists were asked to respond to an open-ended question: What are the top ten the characteristics of a good faculty? The third section started on a new page on which expert panelists were asked to rate a list of 30 characteristics of a good faculty. These characteristics were identified from a systematic review of the literature about the characteristics of a good faculty. Faculty members indicated their perceptions about these characteristics by responding to a questionnaire designed as a Likert-scale with a five-point response choice with $1=$ strongly unimportant, $2=$ unimportant, $3=$ neutral, $4=$ important, and $5=$ strongly important.

Twelve surveys were returned, which constituted a 100\% participation rate. Data were managed using IBM's SPSS Version 22 (Munro, 2001) to save time and create greater flexibility for a multiple-round study (Hasson et al., 2000). Double data entry testing of the frequencies and the ranges in the descriptive statistics was used to assess for outliers and missing data. Descriptive statistics such as the mean, the standard deviation, the frequencies, and the minimum and maximum rating of each item were calculated.

Responses to round one items were analyzed, summarized, and returned to the experts with a new questionnaire for round two (Schmidt, 1997). Feedback from each round was prepared for the panel members in a tabular format that included the group mean rating of each item, the minimum and maximum ratings, the standard deviation, and the frequencies of ratings of each item. The participants were also reminded of his or her rating of the item in the former round (Hasson et al., 2000). The statistics, such as mean and standard deviation (SD), enabled the experts to see where their response was located in relation to that of the group (Schmidt, 1997). A large standard deviation indicated large variations in panelists' rating of that item; in contrast, a small standard deviation reflected small variations in panelists' rating of that item, which indicated consensus (Watson et al., 2008).

Characteristics obtained from the open-ended question were added into the appropriate categories used in the list of items. The analysis yielded seven additional characteristics that expert panelists believed promoted student retention and success. The experts actually listed more than seven characteristics, but many were identical or nearly identical to the characteristics listed in Section III of the survey. The unique seven characteristics were added, bringing the list of factors in Round Two to 37. Table 2 shows the results of the survey questions in Round One, including the means and standard deviations. Characteristics that came out of the open-ended question were assigned "_ " in Table 2.

Table 2:- Results From Round One for the Characteristics of A Good Faculty

\begin{tabular}{|c|c|c|c|c|}
\hline Items & 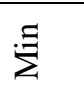 & $\stackrel{\star}{\stackrel{\Xi}{\Sigma}}$ & $\sum_{\Sigma}^{\Xi \Xi}$ & $\hat{\infty}$ \\
\hline \multicolumn{5}{|l|}{ Teaching and learning strategies: } \\
\hline 1. Involving unprepared student. & 3.00 & 5.00 & 4.3333 & .65134 \\
\hline 2. Creating group work on the classroom. & 3.00 & 5.00 & 4.5000 & .67420 \\
\hline 3. Varying teaching methods & 5.00 & 5.00 & 5.0000 & .00000 \\
\hline 4. Classroom management techniques & 3.00 & 5.00 & 4.6364 & .80904 \\
\hline \multicolumn{5}{|l|}{ Knowledge of the subject matter } \\
\hline 5. Academic knowledge & 4.00 & 5.00 & 4.9167 & .28868 \\
\hline 6. Teaching Experience & 3.00 & 5.00 & 4.4167 & .79296 \\
\hline 7. Research and scientific contributions & 4.00 & 5.00 & 4.8333 & .38925 \\
\hline \multicolumn{5}{|l|}{ Personality } \\
\hline 8. Enthusiasm for his teaching (loves his students and his work) & 4.00 & 5.00 & 4.8333 & .38925 \\
\hline 9. Creative & 3.00 & 5.00 & 4.5833 & .79296 \\
\hline 10. Add peace and humor to the class & 4.00 & 5.00 & 4.6667 & .49237 \\
\hline 11. Never give up on student & 2.00 & 5.00 & 4.0833 & 1.08362 \\
\hline 12. Uses discussion topic that interest students. & 4.00 & 5.00 & 4.5833 & .51493 \\
\hline 13. Professionalism & 3.00 & 5.00 & 4.5000 & .79772 \\
\hline
\end{tabular}




\begin{tabular}{|c|c|c|c|c|}
\hline 14. Confident without being arrogant & 3.00 & 5.00 & 4.6667 & .65134 \\
\hline 15. Stimulating student & 4.00 & 5.00 & 4.9167 & .28868 \\
\hline 16. Praise and encourage student & 4.00 & 5.00 & 4.8333 & .38925 \\
\hline 17. Challenge student to think & 3.00 & 5.00 & 4.8182 & .60302 \\
\hline 18. Effectiveness in listening-questioning-responding & 4.00 & 5.00 & 4.7500 & .45227 \\
\hline 19. High expectations for student & 4.00 & 5.00 & 4.8333 & .38925 \\
\hline 20. Ability to engage and inspire student during the learning process & 2.00 & 5.00 & 4.1818 & 1.07872 \\
\hline $\begin{array}{l}\text { 21. Humble and honest (admit he doesn't know the answer if he } \\
\text { doesn't). }\end{array}$ & 4.00 & 5.00 & 4.6364 & .50452 \\
\hline 22. Encourage self-learning & 3.00 & 5.00 & 4.5833 & .79296 \\
\hline 23. Fair with all students. & 3.00 & 5.00 & 4.6667 & .65134 \\
\hline 24. Able to separate between private life and teaching & 4.00 & 5.00 & 4.8333 & .38925 \\
\hline 25. Give continuous and prompt feedback. & 3.00 & 5.00 & 4.4167 & .90034 \\
\hline 26. Effective Communication skills & 3.00 & 5.00 & 4.6667 & .65134 \\
\hline 27. Empathetic & 4.00 & 5.00 & 4.9167 & .28868 \\
\hline 28. Sympathetic & 2.00 & 5.00 & 4.0833 & .99620 \\
\hline 29. Flexible & 3.00 & 5.00 & 4.1667 & .83485 \\
\hline 30. Innovative & 3.00 & 5.00 & 4.5833 & .79296 \\
\hline \multicolumn{5}{|l|}{ 31. Collaborate with colleagues on an ongoing basis } \\
\hline \multicolumn{5}{|l|}{ 32. Goal oriented } \\
\hline \multicolumn{5}{|l|}{ 33. Approachable } \\
\hline \multicolumn{5}{|l|}{ 34. Clinical Experience } \\
\hline \multicolumn{5}{|l|}{ 35. Analytical with sound decision making skills } \\
\hline 36. Has clear objectives on the course dealing with & $\ldots$ & & & \\
\hline 37. Promote students positive behavior & & & & \\
\hline
\end{tabular}

\section{Round Two:-}

The survey in the second round comprised two sections. In the first, participants rated the list of characteristics included in the first round plus the characteristics that were added by the expert panelists. In the second section, experts were asked, again, to add characteristics that they believed to be important to characteristics of a good faculty but had not been included in the list. A total of twelve participants returned Survey Two, which constituted a $100 \%$ participation rate. Data from the second round were analyzed following the same procedure as in the first. Responses to this round were analyzed, summarized, and returned to the experts with a new questionnaire to be used in the third round. Expert panelists rated the importance of the 37 characteristics of a good faculty. Plus, the analysis of the open-ended question yielded five additional characteristics that expert panelists believed to be characteristics of a good faculty, bringing the list of characteristics in Round Three to 42. Table 3 shows the results from the survey questions in Round Two, including the means and standard deviations. Characteristics that came out of the open-ended question were assigned "__ " in Table 3.

Table 3:- Results from Round Two for the Characteristics of A Good faculty

\begin{tabular}{|c|c|c|c|c|}
\hline Items & Mini & Max & Mean & SD \\
\hline \multicolumn{5}{|l|}{ Teaching and learning strategies: } \\
\hline 1. Involving unprepared student. & 3.00 & 5.00 & 4.27 & 0.65 \\
\hline 2. Creating group work on the classroom. & 3.00 & 5.00 & 4.45 & 0.69 \\
\hline 3. Varying teaching methods & 4.00 & 5.00 & 4.91 & 0.30 \\
\hline 4. Classroom management techniques & 4.00 & 5.00 & 4.70 & 0.48 \\
\hline \multicolumn{5}{|l|}{ Knowledge of the subject matter } \\
\hline 5. Academic knowledge & 5.00 & 5.00 & 5.00 & 0.00 \\
\hline 6. Teaching Experience & 3.00 & 5.00 & 4.55 & 0.69 \\
\hline 7. Research and scientific contributions & 4.00 & 5.00 & 4.73 & 0.47 \\
\hline \multicolumn{5}{|l|}{ Personality } \\
\hline 8. Enthusiasm for his teaching (loves his students and his work) & 4.00 & 5.00 & 4.82 & 0.40 \\
\hline 9. Creative & 3.00 & 5.00 & 4.55 & 0.69 \\
\hline
\end{tabular}




\begin{tabular}{|c|c|c|c|c|}
\hline 10. Add peace and humor to the class & 4.00 & 5.00 & 4.64 & 0.50 \\
\hline 11. Never give up on student & 3.00 & 5.00 & 4.45 & 0.69 \\
\hline 12. Uses discussion topic that interest students & 4.00 & 5.00 & 4.55 & 0.52 \\
\hline 13. Professionalism & 4.00 & 5.00 & 4.73 & 0.47 \\
\hline 14. Confident without being arrogant & 4.00 & 5.00 & 4.91 & 0.30 \\
\hline 15. Stimulating student & 4.00 & 5.00 & 4.82 & 0.40 \\
\hline 16. Praise and encourage student & 4.00 & 5.00 & 4.82 & 0.40 \\
\hline 17. Challenge student to think & 4.00 & 5.00 & 4.64 & 0.50 \\
\hline 18. Effectiveness in listening-questioning-responding & 4.00 & 5.00 & 4.82 & 0.40 \\
\hline 19. High expectations for student & 3.00 & 5.00 & 4.18 & 0.75 \\
\hline 20. Ability to engage and inspire student during the learning process & 4.00 & 5.00 & 4.64 & 0.50 \\
\hline $\begin{array}{l}\text { 21. Humble and honest (admit he doesn't know the answer if he } \\
\text { doesn't). }\end{array}$ & 4.00 & 5.00 & 4.55 & 0.52 \\
\hline 22. Encourage self-learning & 4.00 & 5.00 & 4.91 & 0.30 \\
\hline 23. Fair with all students. & 5.00 & 5.00 & 5.00 & 0.00 \\
\hline 24. Able to separate between private life and teaching & 3.00 & 5.00 & 4.45 & 0.69 \\
\hline 25. Give continuous and prompt feedback. & 4.00 & 5.00 & 4.73 & 0.47 \\
\hline 26. Effective Communication skills & 4.00 & 5.00 & 4.91 & 0.30 \\
\hline 27. Empathetic & 2.00 & 5.00 & 4.09 & 0.94 \\
\hline 28. Sympathetic & 2.00 & 5.00 & 3.82 & 1.08 \\
\hline 29. Flexible & 4.00 & 5.00 & 4.73 & 0.47 \\
\hline 30. Innovative & 4.00 & 5.00 & 4.82 & 0.40 \\
\hline 31. Collaborate with colleagues on an ongoing basis & 4.00 & 5.00 & 4.55 & 0.52 \\
\hline 32. Goal oriented & 4.00 & 5.00 & 4.73 & 0.47 \\
\hline 33. Approachable & 3.00 & 5.00 & 4.20 & 0.79 \\
\hline 34. Clinical Experience & 3.00 & 5.00 & 4.40 & 0.84 \\
\hline 35. Analytical with sound decision making skills & 3.00 & 5.00 & 4.30 & 0.82 \\
\hline 36. Has clear objectives on the course dealing with & 4.00 & 5.00 & 4.80 & 0.42 \\
\hline 37. Promote students positive behavior & 4.00 & 5.00 & 4.60 & 0.52 \\
\hline 38. Being culturally aware & & & & \\
\hline 39. Being culturally sensitive & & & & \\
\hline 40. Being role model & & & & \\
\hline 41. Emotional intelligent and trust worthiness. & - & & & \\
\hline 42. Leadership skills & & & & \\
\hline
\end{tabular}

\section{Round Three:-}

As in the second round, participants in the third round rated the list of 42 characteristics of a good faculty. A total of twelve returned Survey Three, which constituted a 100\% participation rate. No new characteristics were added by the experts in this round. In analyzing the third round, any characteristic with a mean score of 4.00 out of 5.00 is considered that consensus had been achieved for that characteristic. In determining the agreement level, we calculate the percentage of participants whom rated that characteristic as an "Important" or "Strongly Important". A 100\% agreement level was achieved in 40 out of the 42 characteristics. Experts believed that both being empathetic and sympathetic are not among the characteristics of a good faculty. However, a 100 agreement level was achieved in 17 characteristics, similarly, a 100 agreement level was achieved in 17 characteristics, while a 83 agreement level was achieved in two characteristics only. A 75 agreement level was achieved in three characteristics, a 66 and 58 agreement levels were achieved in one and two characteristics respectively. Table 4 shows the results from the survey questions in Round Three, including the means, standard deviations, and agreement level. 
Table 4: Results from Round Three for the Characteristics of a Good faculty

\begin{tabular}{|c|c|c|c|c|}
\hline Items & Mean & SD & Freq & Agr \% \\
\hline \multicolumn{5}{|l|}{ Teaching and learning strategies: } \\
\hline 1. Involving unprepared student. & 4.33 & 0.65 & $\mathrm{~N}=1, \mathrm{Im}=6, \mathrm{SI}=5$ & 91 \\
\hline 2. Creating group work on the classroom. & 4.50 & 0.67 & $\mathrm{~N}=1 \mathrm{I}=4 \mathrm{SI}=7$ & 91 \\
\hline 3. Varying teaching methods & 4.83 & 0.39 & $\mathrm{I}=2 \quad \mathrm{SI}=10$ & 100 \\
\hline 4. Classroom management techniques & 4.75 & 0.45 & $\mathrm{I}=2 \mathrm{SI}=10$ & 100 \\
\hline \multicolumn{5}{|l|}{ Knowledge of the subject matter } \\
\hline 5. Academic knowledge & 4.92 & 0.29 & $\mathrm{I}=1 \mathrm{SI}=11$ & 100 \\
\hline 6. Teaching Experience & 4.58 & 0.67 & $\mathrm{~N}=1 \mathrm{I}=3 \mathrm{SI}=8$ & 91 \\
\hline 7. Research and scientific contributions & 4.75 & 0.45 & $\mathrm{I}=3 \quad \mathrm{SI}=9$ & 100 \\
\hline \multicolumn{5}{|l|}{ Personality } \\
\hline $\begin{array}{l}\text { 8. Enthusiasm for his teaching (loves his students and } \\
\text { his work) }\end{array}$ & 4.82 & 0.40 & $\mathrm{I}=2 \mathrm{SI}=9$ & 100 \\
\hline 9. $\quad$ Creative & 4.50 & 0.67 & $\mathrm{~N}=1 \mathrm{I}=5 \quad \mathrm{SI}=6$ & 91 \\
\hline 10. Add peace and humor to the class & 4.50 & 0.67 & $\mathrm{~N}=1 \mathrm{I}=4 \mathrm{SI}=7$ & 91 \\
\hline 11. Never give up on student & 4.42 & 0.67 & $\mathrm{~N}=1 \mathrm{I}=4 \mathrm{SI}=7$ & 91 \\
\hline 12. Uses discussion topic that interest students. & 4.42 & 0.67 & $\mathrm{~N}=1 \mathrm{I}=5 \mathrm{SI}=6$ & 91 \\
\hline 13. Professionalism & 4.58 & 0.67 & $\mathrm{~N}=1 \mathrm{I}=3 \mathrm{SI}=8$ & 91 \\
\hline 14. Confident without being arrogant & 4.83 & 0.39 & $\mathrm{I}=2 \mathrm{SI}=10$ & 100 \\
\hline 15. Stimulating student & 4.75 & 0.45 & $\mathrm{I}=3 \mathrm{SI}=9$ & 100 \\
\hline 16. Praise and encourage student & 4.75 & 0.45 & $\mathrm{I}=3 \mathrm{SI}=9$ & 100 \\
\hline 17. Challenge student to think & 4.50 & 0.67 & $\mathrm{~N}=1 \mathrm{I}=4 \mathrm{SI}=7$ & 91 \\
\hline 18. Effectiveness in listening-questioning-responding & 4.58 & 0.67 & $\mathrm{~N}=1 \mathrm{I}=3 \mathrm{SI}=8$ & 91 \\
\hline 19. High expectations for student & 4.08 & 0.79 & $\mathrm{~N}=3 \mathrm{I}=5 \mathrm{SI}=4$ & 75 \\
\hline $\begin{array}{l}\text { 20. Ability to engage and inspire student during the } \\
\text { learning process }\end{array}$ & 4.58 & 0.51 & $\mathrm{I}=5 \mathrm{SI}=7$ & 100 \\
\hline $\begin{array}{l}\text { 21. Humble and honest (admit he doesn't know the } \\
\text { answer if he doesn't). }\end{array}$ & 4.50 & 0.52 & $\mathrm{I}=6 \mathrm{SI}=6$ & 100 \\
\hline 22. Encourage self-learning & 4.83 & 0.39 & $\mathrm{I}=2 \mathrm{SI}=10$ & 100 \\
\hline 23. Fair with all students. & 5.00 & 0.00 & $\mathrm{SI}=12$ & 100 \\
\hline 24. Able to separate between private life and teaching & 4.42 & 0.67 & $\mathrm{~N}=1 \mathrm{I}=5 \mathrm{SI}=6$ & 91 \\
\hline 25. Give continuous and prompt feedback. & 4.75 & 0.45 & $\mathrm{I}=3 \mathrm{SI}=9$ & 100 \\
\hline 26. Effective Communication skills & 4.83 & 0.39 & $\mathrm{I}=2 \mathrm{SI}=10$ & 100 \\
\hline 27. Empathetic & $3.83 *$ & 1.02 & $\mathrm{UN}=1 \mathrm{~N}=4 \quad \mathrm{I}=3 \quad \mathrm{SI}=4$ & 58 \\
\hline 28. Sympathetic & $3.75^{*}$ & 1.11 & $\mathrm{UN}=2 \mathrm{~N}=3 \quad \mathrm{I}=3 \quad \mathrm{SI}=4$ & 58 \\
\hline 29. Flexible & 4.50 & 0.67 & $\mathrm{~N}=1 \mathrm{I}=4 \mathrm{SI}=7$ & 66 \\
\hline 30. Innovative & 4.75 & 0.62 & $\mathrm{~N}=1 \mathrm{I}=5 \mathrm{SI}=6$ & 91 \\
\hline 31. Collaborate with colleagues on an ongoing basis & 4.58 & 0.51 & $\mathrm{I}=5 \quad \mathrm{SI}=7$ & 100 \\
\hline 32. Goal oriented & 4.75 & 0.45 & $\mathrm{I}=3 \mathrm{SI}=9$ & 100 \\
\hline 33. Approachable & 4.33 & 0.65 & $\mathrm{~N}=1 \mathrm{I}=6 \mathrm{SI}=5$ & 91 \\
\hline 34. Clinical Experience & 4.42 & 0.79 & $\mathrm{~N}=2 \mathrm{I}=3 \quad \mathrm{SI}=7$ & 83 \\
\hline 35. Analytical with sound decision making skills & 4.33 & 0.78 & $\mathrm{~N}=2 \mathrm{I}=4 \mathrm{SI}=6$ & 83 \\
\hline 36. Has clear objectives on the course dealing with & 4.75 & 0.62 & $\mathrm{~N}=1 \mathrm{I}=1 \mathrm{SI}=10$ & 91 \\
\hline 37. Promote students positive behavior & 4.58 & 0.67 & $\mathrm{~N}=1 \mathrm{I}=3 \mathrm{SI}=8$ & 91 \\
\hline 38. Being culturally aware & 4.42 & 0.67 & $\mathrm{~N}=1 \mathrm{I}=5 \mathrm{SI}=6$ & 91 \\
\hline 39. Being culturally sensitive & 4.17 & 0.83 & $\mathrm{~N}=3 \mathrm{I}=4 \mathrm{SI}=5$ & 75 \\
\hline 40. Being role model & 4.67 & 0.49 & $\mathrm{I}=4 \mathrm{SI}=8$ & 100 \\
\hline 41. Emotional intelligent and trust worthiness. & 4.58 & 0.67 & $\mathrm{~N}=1 \mathrm{I}=3 \quad \mathrm{SI}=8$ & 91 \\
\hline 42. Leadership skills & 4.45 & 1.04 & $\mathrm{UN}=1 \mathrm{~N}=1 \mathrm{I}=1 \quad \mathrm{SI}=8$ & 75 \\
\hline
\end{tabular}

Note. Agr \% = agreement level, $\mathrm{UN}=$ unimportant, $\mathrm{N}=$ neutral, $\mathrm{I}=$ important, $\mathrm{SI}=$ strongly important factors were added by the experts and were not rated in this round.

* indicates the factors that are not important from students' perspective 


\section{Discussion:-}

The present study aimed to examine the characteristics of a good faculty in a nursing program in Saudi Arabia. In the present study, a total of 42 characteristics of a good faculty were identified after three round of Delphi survey. The top five characteristics of a good faculty in the present study were fair to all students, good academic knowledge, uses variety of teaching methods, encourage self-learning, and effective communication skills. Recently, a previous study reported top three qualities of a good teacher in the faculty of medicine and dentistry were subject knowledge, enthusiasm, and good communication skills (Singh et al., 2013). In another study, the top three qualities of a good teacher in the faculty of dentistry were respectful to students, good communication skills, and subject knowledge (Al-Jobair and AlSarheed, 2016). A recent review indicated that a good teacher should have an engaging personality, academic knowledge, and teaching skills that are exhibited through enthusiasm and passion (Benekos, 2016). In addition, Das et al. (1996) reported that the most important quality of a good teacher was willingness of faculty to help the students as identified by the students and the teacher in the faculty of medicine and health sciences. In addition, other reported qualities of a good teacher were academic knowledge, presentation skills, focused on essentials of information, good communication skills, and who respected student opinion (Das et al., 1996).

Most of the previous studies reported that the knowledge of subjects was considered a core characteristic of a good teacher. Adediwura and Tayo (2007) reported a high correlation between subject knowledge and what teacher teaches. Singh et al. (2013) reported that the 'Knowledge of subject' was highest rated by the faculty irrespective of gender, field, cultural background or teaching experience. Knowledge of subject is an intellectual quality which can be learned and has been observed to be an imperative quality in the previous studies across all disciplines (Ballantyne, 2007; Levy, 2006; Kelly, 2007).

In the present study, other important qualities of good teacher were identified as follow: enthusiasm, confident, classroom management techniques, innovative, research and scientific contributions, goal oriented, praise and encourage student, and give continuous and prompt feedback. A previous study identified that good feedback, interactive teaching, and scholarly activity among other qualities of a good teacher (Jahan et al., 2008). Similar to present study, in the previous study, enthusiasm was considered to be the second highest rated characteristic of a good teacher (Singh et al., 2013). In addition, Yilmaz (2011) indicated that a good teacher should have enthusiasm and encourage student to learn. Similarly, Duvivier et al. (2009) indicated that the enthusiasm was the most important theme in the quality of clinical skills lab teachers. Furthermore, Tang, et al. (2005) reported that "personality related" quality was important to differentiate an effective teacher from an ineffective teacher in the faculty of nursing. Moreover, other studies indicated enthusiasm was one of the important qualities of an effective teacher in the faculty of dentistry (Al-Jobair and AlSarheed, 2016; Hand, 2006; Schönwetter et al., 2006). A previous review identified enthusiasm as one of the important theme for effective teaching in the faculty of medicine (Sutkin et al., 2008).

In the present study, experts believed that both being empathetic and sympathetic are not among the characteristics of a good faculty. However, a previous study indicated that the good qualities of the clinical teachers include caring, motivating, and empathetic as identified by dental students (Jahangiri et al., 2013). In addition, a recent study identified top five characteristics of effective simulation teachers were motivation, expertise, available, caring, and feedback (McAndrew et al., 2016).

The present study had several potential limitations. The number of participants was small, included only 12 participants. In addition, only faculty perspective was identified. In the future study, student perspective on the characteristics of a good faculty in the nursing education in Saudi Arabia is recommended. Furthermore, the present study conducted in a single center therefore, the results cannot be generalized. Moreover, a future study including both students and faculty members from the different nursing colleges in Saudi Arabia is recommended.

\section{Conclusions:-}

Effective teaching in the nursing education is an essential to produce a good quality nursing professionals in the Saudi Arabia. In the present study, teaching and learning strategies, subject knowledge, and the personality attributes all were characteristics of a good faculty in the nursing college. However, academic knowledge, teaching methods, and communication skills were the top qualities of a good faculty. 


\section{Acknowledgements:-}

The authors are thankful to the Deanship of Scientific Research, College of Nursing Research Center at King Saud University for funding this research

\section{Conflict of interest Disclosure:-}

The authors declare that there is no conflict of interest regarding the publication of this paper.

\section{References:-}

1. Adediwura, A., \& Tayo, B.(2007). Perception of teachers' knowledge, attitude and teaching skills as predictor of academic performance in Nigerian secondary schools. Educ Res Rev, 2(7):165-171.

2. Alamri, M. (2011). Higher education in Saudi Arabia. Journal of Higher Education Theory \& Practice, 11(4): $88-91$.

3. ALHussain, A. Z., Murphree Jr, E. L., \& Bixler, C. H. (2012). Barriers to knowledge management in Saudi Arabia. Journal of Knowledge Globalization, 5(1): 47-75.

4. Al-Jobair, A.M., \& AlSarheed, M.A. (2016). Saudi dental students' opinions on the qualities and attributes of an effective dental teacher. Adv Med Educ Pract, 7:533-539.

5. Arnon, S., \& Reichel, N. (2007). Who is the ideal teacher? Am I? Similarity and difference in perception of students of education regarding the qualities of a good teacher and of their own qualities as teachers. Teachers and Teaching: theory and practice, 13(5):441-464.

6. Bakx, A., Koopman, M., de Kruijf, J., \& den Brok, P. (2015). Primary school pupils' views of characteristics of good primary school teachers: an exploratory, open approach for investigating pupils' perceptions. Teachers \& Teaching, 21(5):543-564.

7. Ballantyne, J. (2007). Integration, contextualization and continuity: three themes for the development of effective music teacher education programmes. Int j Music Educ, 25(2):119-136.

8. Benekos, P. J. (2016). How to be a Good Teacher: Passion, Person, and Pedagogy. Journal of Criminal Justice Education, 27(2):225-237.

9. Bunting, C. (2006). Good Teachers. Clearing House, 79(6):245-246.

10. Cantrill, J. Sibbald, B. \& Buetow, S. (1996). The Delphi and nominal group techniques in health services research. International Journal of Pharmacy Practice, 4(2):67-74.

11. Carr, D. (1999). Is Teaching a Skill? http://www.pantaneoto.co.uk/issue8/Carr.

12. Clayton, M. J. (1997). Delphi: A technique to harness expert opinion for critical decision-making tasks in education. Educational Psychology, 17(4):373-386.

13. Dalkey, N., \& Helmer, O. (1963). An experimental application of the Delphi method to the use of experts. Management Science, 9(3):458-467.

14. Das, M., El-Sabban, F., \& Bener, A. (1996). Student and faculty perceptions of the characteristics of an ideal teacher in a classroom setting. Medical Teacher, 18 (2):141-146.

15. Dewey, J. (1938). Experience and Education. New York: McMillan

16. Duvivier, R.J., Van Dalen, J., Van der Vleuten, C.P., \& Scherpbier, A.J. (2009). Teacher perceptions of desired qualities, competencies and strategies for clinical skills teachers. Med Teach, 31(7):634-41.

17. Friedman, L.M., Furberg, C.D., \& DeMets, D.L. (1998). Fundamentals of clinical trials (3rd ed.). New York, NY: Springer.

18. Gándara, P., \& Santibañez, L. (2016). THE TEACHERS. Educational Leadership, 73(5), 32-37.

19. Glanz, J. (1993). What Makes a Good Teacher: Reflections on some characteristics central to the educational enterprise. Educational Studies. Pp. i, 203.

20. Glanz, J. (1995). What Makes a Good Teacher? Educational Studies, 26(1/2), 65.

21. Green, B., Jones, M., Hughes, D., \& Willimas, A. (1999). Applying the Delphi technique in a study of GP's information requirements. Health and Social Care in the Community, 7(3): 198-205.

22. Hamdan, A. K. (2014). The reciprocal and correlative relationship between learning culture and online education: A case from Saudi Arabia. International Review of Research in Open \& Distance Learning, 15(1):309-336.

23. Hammer, D., Piascik, P., Medina, M., Pittenger, A., Rose, R., Creekmore, F et al. (2010). Recognition of teaching excellence. Am J Pharm Educ, 74(9):164.

24. Hand, J.S. (2006). Identification of competencies for effective dental faculty. J Dental Educ, 70(9):937-947.

25. Hasson, F., Keeney, S., \& McKenna, H. (2000). Research guidelines for the Delphi survey technique. Journal of Advanced Nursing, 32(4):1008-1015. 
26. Hogarth, R. M. (1978). A note on aggregating opinions. Organizational Behavior \& Human Performance, 21(1):40-46.

27. Jahan, F., Sadaf, S., Kalia, S., Khan, A., \& Hamza, H.B. (2008). Attributes of an effective clinical teacher: a survey on students' and teachers' perceptions. J Coll Physicians Surg Pak, 18(6):357-61.

28. Jahangiri, L., McAndrew, M., Muzaffar, A., \& Mucciolo, T.W. (2013). Characteristics of effective clinical teachers identified by dental students: a qualitative study. Eur J Dent Educ, 17(1):10-8.

29. Jenkins, R. (2016). What Makes a Good Teacher?. Chronicle Of Higher Education, 62(39):A25

30. Jones, J., \& Hunter D. (1995). Consensus methods for medical and health services research. British Medical Journal, 311(7001):376-380.

31. Keeney, S., Hasson, F., \& McKenna, H. (2006). Consulting the oracle: Ten lessons from using the Delphi technique in nursing research. Journal of advanced nursing, 53(2):205-212.

32. Kelly, C. (2007). Student's perceptions of effective clinical teaching revisited. Nurse Educ Today, 27(8):885892.

33. Leblanc, R. (1998). Good teaching: The top ten requirements. The Teacher Professor, 12(6), cited in CORE. Colorado State University, College of Business. Retrieved from http://biz.colostate.edu/mti/tips/pages/GoodTeaching.aspx

34. Levy, J.B. (2006) As a last resort, ask the students: what they say makes someone an effective law teacher. Maine Law Rev, 58(1):50-98.

35. Loughlin, K., \& Moore L. (1979). Using Delphi to achieve congruent objectives and activities in a pediatrics department. Journal of Medical Education 54:101-106.

36. Manchanda, B. (2010). What is good teaching? Articles base. Retrieved from http://www.articlesbase.com/college-and-university-articles/what-is-good-teaching-

37. McAndrew, M., Mucciolo, T.W., \& Jahangiri, L. (2016) Characteristics of Effective Simulation (Preclinical) Teachers as Identified by Dental Students: A Qualitative Study. J Dent Educ, 80(11):1282-1293.

38. McKenna, H. P. (1994). The Delphi technique: A worthwhile research approach for nursing? Journal of Advanced Nursing, 19(6):1221-1225.

39. McKenna, H., \& Hasson, F. (2002). A study of skill mix issues in midwifery: A multi-method approach. Journal of Advanced Nursing, 37(1):52-61.

40. Miller, P. (2012). Ten Characteristics of a Good Teacher. In English Teaching Forum (Vol. 50, No. 1, pp. 3638).

41. Miron, M., \& Segal, E. (1978). "The good university teacher" as perceived by the students. Higher Education, 7(1):27-34

42. Mitchell, V. W. (1991). The Delphi technique: An exposition and application. Technology Analysis \& Strategic Management, 3(4):333.

43. Nieswiadomy, R. M. (2008). Foundations of nursing research (5th ed.). New Jersey: Pearson Education.

44. Onsman, A. (2011). It is better to light a candle than to ban the darkness: Government led academic development in Saudi Arabian universities. Higher Education: The International Journal of Higher Education and Educational Planning, 62(4):519-532.

45. Orlando, M. (2013, January 14). Nine characteristics of a great teacher. Faculty Focus: Higher Ed Teaching Strategies form Magna Publications. Retrieved from http://www.facultyfocus.com/articles/philosophy-ofteaching/nine-characteristics-of-a-greatteacher/

46. Passannante, M., Restifo, R. \& Reichman, L. (1993). Preventive therapy for the patient with both universal indication and contraindication for isoniazid. Chest, 103(3):825-831.

47. Polit, D., \& Beck, C. (2004). Nursing research: Principles and methods. (2nd ed.). Philadelphia PA: Lippincott Williams \& Wilkins.

48. Schmidt, R. (1997). Managing Delphi surveys using nonparametric statistical techniques. Decision Sciences, 28(3):763-774.

49. Schönwetter, D.J., Lavigne, S., Mazurat, R., \& Nazarko, O. (2006). Students' perceptions of effective classroom and clinical teaching in dental and dental hygiene education. J Dental Educ, 70(6):624-635.

50. Shulman, L. S. (2004). The wisdom of practice: Essays on teaching, learning, and learning to teach. San Francisco: Jossey Bass.

51. Singh, S., Pai, D.R., Sinha, N.K., Kaur, A., Soe, H.H., \& Barua, A. (2013). Qualities of an effective teacher: what do medical teachers think? BMC Med Educ, 13:128.

52. Sumsion T. (1998). The Delphi technique: An adaptive research tool. British Journal of Occupational Therapy 61(4):153-156. 
53. Sutkin, G., Wagner, E., Harris, I., \& Schiffer, R. (2008). What makes a good clinical teacher in medicine? A review of the literature. Academic Medicine, 83(5):452-466.

54. Tang, F.I., Chou, S.M., \& Chiang, H.H. (2005). Students' perceptions of effective and ineffective clinical instructors. J Nurse Educ, 44(4):187-192.

55. Taylor, P. H. (1962). Children's evaluations of the characteristics of the good teacher. British Journal of Educational Psychology, 32(P3):258-266.

56. Watson, R., McKenna, H., Cowman, S., \& Keady, J. (2008). Nursing research: Designs and methods. (1st ed.). New York: Churchill Livingstone/Elsevier.

57. Williams, P., \& Webb, C. (1994). The Delphi technique: a methodological discussion. Journal Of Advanced Nursing, 19(1):180-186.

58. Yilmaz, A. (2011). Quality problem in teaching profession: Qualities teacher candidates feel to be required of teachers. Educ Res Rev, 6(14):812-823. 